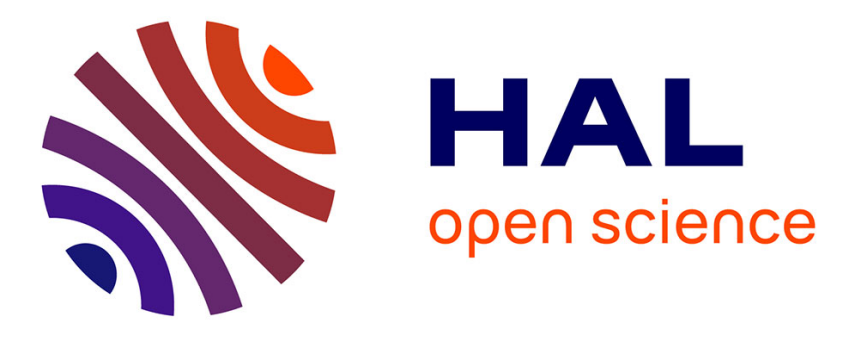

\title{
Model reference-based vehicle lateral control for lane departure avoidance
}

André Benine-Neto, Stefano Scalzi, Said Mammar, Mariana Netto, Benoît Lusetti

\section{- To cite this version:}

André Benine-Neto, Stefano Scalzi, Said Mammar, Mariana Netto, Benoît Lusetti. Model referencebased vehicle lateral control for lane departure avoidance. International Journal of Vehicle Autonomous Systems, 2014, 12 (3), pp.284-306. 10.1504/IJVAS.2014.063044 . hal-01023288

\section{HAL Id: hal-01023288 \\ https://hal.science/hal-01023288}

Submitted on 11 Jul 2014

HAL is a multi-disciplinary open access archive for the deposit and dissemination of scientific research documents, whether they are published or not. The documents may come from teaching and research institutions in France or abroad, or from public or private research centers.
L'archive ouverte pluridisciplinaire HAL, est destinée au dépôt et à la diffusion de documents scientifiques de niveau recherche, publiés ou non, émanant des établissements d'enseignement et de recherche français ou étrangers, des laboratoires publics ou privés. 


\title{
Model Reference Based Vehicle Lateral Control for Lane Departure Avoidance
}

\author{
André Benine-Neto* \\ Laboratoire de l'intégration, du matériau au système (IMS) \\ Bordeaux \\ F33405, Talence Cedex, France \\ E.Mail: andre.benine-neto@u-bordeaux.fr \\ *corresponding author

\section{Stefano Scalzi} \\ Univ. of Rome Tor Vergata, Electronic Eng. Department \\ 1 via del Politecnico, \\ 00133, Rome, Italy \\ E-mail: stefano.scalzi@uniroma2.it
}

CNRS : UMR5218 - Université de Bordeaux - Institut Polytechnique de

\section{Saïd Mammar}

IBISC - EA 4526 UEVE

40 rue du Pelvoux CE1455,

91020, Evry, Cedex, France

E-mail: said.mammar@ibisc.univ-evry.fr

\section{Mariana Netto and Benoit Lusetti}

\section{IFSTTAR - LIVIC}

14 Route de la Minière,

78000, Versailles, France

E-mail: mariana.netto@ifsttar.fr and benoit.lusetti@ifsttar.fr

\begin{abstract}
:
This paper presents the design and practical implementation of a lane departure avoidance assistance for passenger vehicles based on a state feedback dynamic controller. The road curvature is taken into account as an internal model to ensure convergence of the lateral offset to zero at steady state, even in curvy roads. Lyapunov theory and Bilinear Matrix Inequalities, including bounds in the control input and constraints for poles clustering are used to minimise the reachable set of the vehicle after activation of the assistance. The proposed control strategy is simulated in CarSim environment and successfully tested on a prototype vehicle.
\end{abstract}

Keywords: Invariant Sets; BMI: Bilinear Matrix Inequality; Driving Assistance Systems; Vehicle Lateral Control; Lane Departure Avoidance. 
Reference to this paper should be made as follows: Benine-Neto, A., Scalzi, S., Mammar S., Netto, M. and Lusetti, B. (2012). 'Model Reference Based Vehicle Lateral Control for Lane Departure Avoidance', Int. J. Vehicle Autonomous Systems, Vol. x, No. x, pp.xxx-xxx.

Biographical notes: André Benine-Neto received his Dipl.-Ing. degree from Universidade Estadual de Campinas, Campinas, Brazil, in 2006, the Ph.D. degree in automatic control from Université d'Evry, Evry, France in 2011. He worked from 2006 to 2008 for Ford Motor Company as product development engineer of engine components in Camaçari, Brazil. From 2009 to 2011 he carried out research on driver assistance systems for unintended lane departure at LIVIC/IFSTTAR in Versailles, France. From 2011 to 2012 he held a position as assistant lecturer at Université Pierre et Marie Curie, Paris with research activities on off-road unmanned ground vehicles at ISIR, Paris. He is currently associate professor at Université Bordeaux on control engineering and his research interests at IMS laboratory in Bordeaux include driver assistance systems, vehicle longitudinal and lateral control, robust control and fractional systems.

Stefano Scalzi was born in Albano, Roma, Italy, in 1979. He received the degree in Automation engineering at the University of Rome Tor Vergata. From June 2004 to May 2005 he attended the master at University of Camerino (Marche) in "Racing Car Engineer". Form October 2005 and April 2006 he worked in Ferrari S.p.a in the reliability department (road tests and data analysis). In 2009 received the PHD at the University of Rome Tor Vergata in "Sensory and Learning Systems Engineering". After the post-doc at LIVIC (Vehicle-InfrastructureDriver Interactions Research Unit), Versailles, France in 2010 he is currently working at the University of Rome Tor Vergata.

Saïd Mammar received the Dipl.-Ing. degree from the Ecole Supérieure d'Electricité, Gif-sur-Yvette, France, in 1989, the Ph.D. degree in automatic control from the Université Paris XI, Orsay, France, in 1992, and the Habilitation to Direct Research degree from the Evry val d'Essonne University, France, in 2001. From 1992 to 1994, he held a research position with the French National Institute on Transportation Research and Safety, Versailles, France, where he was involved in research on traffic network control. From 1994 to 2002, he was an Assistant Professor with the Evry val d'Essonne University, where he has been a Professor since 2002. From 2006 to September 2009, he was a Scientific and University Attaché with the French Embassy Hague, The Netherlands. He is the Head of Computer Science, Integrative Biology and Complex Systems Lab (IBISC), Evry Val d'Essonne, University since January 2010. He is also the Vice President of International Affairs since January 2012. His actual research interests include robust control, vehicle longitudinal and lateral control for driving assistance, and intelligent transportation systems. He has been supervisor of 30 $\mathrm{PhD}$ students and several of Master students. He has been leader and involved in many industry, government and EU-funded research projects.

Mariana Netto received her B.Sc. degree in electronic engineering and her M.Sc. degree in automatic control from the Federal University of Rio de Janeiro, Brazil, in 1995 and 1997, respectively, and she obtained her Ph.D. degree in automatic control from the Université Paris Sud, France, in collaboration with the Massachusetts Institute of Technology, USA, in 2001. After one year as assistant professor within the Universite Paris Sud, she has integrated, as a researcher, in 2002, the French Institute for Transports IFSTTAR (French Institute of Science and Technology for Transports, Development and Networks). Among her research activities, Mariana Netto leads the partner IFSTTAR in the European Network of Excellence HYCON2; she is member of the IFAC 
Model Reference Based Vehicle Lateral Control for Lane Departure Avoidance 3

technical Committee 'Transportation Systems' and of the iMobility Forum Expert Community, that works to give advice to the European Commission on the transportaion research priority areas. Her research interests are focused on linear and nonlinear control, including the control of nonlinearly parameterized systems, on intelligent transportation systems for improved safety and mobility of the citizens and on human-machine systems for translating technology to the human welfare. She counts more than 80 publications including journal, conference papers and deliverables. Mariana Netto has obtained her 'Habilitation à Diriger des Recherches' degree, also from the Université Paris Sud, France, in 2013.

B. Lusetti received a master degree in industrial systems from Université Evry Val d'Essonne, France, in 2002. He is currently engineer in the Vehicle-InfrastructureDrivers Interactions joint research unit (LIVIC IFSTTAR), in Versailles, France. He works on development and testing of experimental vehicle prototypes.

\section{Introduction}

Many highway accidents occur due to unintended lane departure, therefore intelligent vehicles and automated highway systems have attracted a growing attention in the last years. An overview of the research activity presented by Shladover (2007) and the progress done in the last decade shown by Urmson et al. (2008). The entirely or partially automation of driving task aims to increase safety by reducing accidents and the driver's workload.In order to prevent vehicle crash due to inattention, illness or sleepiness, vehicles have increasingly been equipped with electronic control systems that provide active safety.

Kullack et al. (2008) have proposed a lane departure warning system. Such systems are also available in some commercialised passenger vehicles. Other works address the problem of combining the driver and the automatic lane keeping control action, either by sharing or overriding the driving task with the driver. It can be noticed from the literature concerning the lane keeping problem that several control algorithms are employed. Mammar et al. (2010), Hessburg and Tomizuka (1991) and Wu et al. (2008) make use of fuzzy rule-based controllers. Model predictive control is applied by Falcone et al. (2007) using a nonlinear vehicle model to predict the system evolution for the development of an active steering system for autonomous vehicles. $H_{\infty}$ techniques are explored in the design of an assistance system (Raharijaona et al., 2004) and an automatic lane keeping system for highway scenario (Cerone et al., 2002). The use of PID is employed in many papers. In the framework of autonomous vehicles some techniques involve: a gain scheduling based proportional feedback from the lateral offset (Broggi et al., 1999); a PID based on a weighted sum of the heading error and the lateral offset with feedforward term from curvature (Cremean et al., 2006); and the yaw angle and a nonlinear term proportional to the lateral offset are used as measurements to design the steering controller (Thrun et al., 2006). As for driving assistance systems, Takahashi and Asanuma (2000) applies a feedforward on the road curvature and feedback PD on vehicle lateral position and heading angle; and a comparison of PID, fuzzy, $H_{\infty}$, and adaptive controllers is presented by Chaib et al. (2004). Optimal preview control theory is explored by MacAdam (1981) and Kang et al. (2008), who also makes use of a feedforward term. Linear and nonlinear sliding mode controllers with feedback of the lateral displacement and yaw rate are designed by Ackermann et al. (1995). Control synthesis based on Lyapunov techniques are presented by Rosseter and Gerdes (2006) in which a potential field control structure for a vehicle with steer-by-wire is introduced . Kritayakirana 
and Gerdes (2012) carried out tests on an autonomous vehicle equipped with this controller. Minoiu-Enache et al. (2009a,b) proposed to compute closed-loop invariant sets for the lane keeping system by means of LMI (and BMI) optimisation based on Lyapunov stability conditions. Benine-Neto et al. (2013) applied similar techniques to design lane keeping system based on piecewise affine controllers in order to take into account the nonlinear behaviour of the lateral tyre forces.

In the framework of advanced driving assistance systems (ADAS), many possibilities are shown in the literature concerning the activation strategies of lane keeping systems. Eidehall et al. (2005) proposes a system that perceives the intention of the driver based on the vehicle dynamics and tracks the environment (road geometry, obstacles/vehicles on current and adjacent lanes) to compute the risk of the manoeuvre using the time to lane crossing to predict a collision. Fujiwara and Adachi (2003) defines a time-varying parameter, in order to reduce the conflicts between the driver and the system assistance, so that the control action increases when the driver steering wheel torque decreases; Leelavansuk et al. (2002) make use of a weight (between zero and one) which multiplies the proposed LQ steering control in order to reduce the interference with the driver. In the ADAS proposed by Cerone et al. (2009) and Rosseter and Gerdes (2006) an automatic lane keeping is combined with the driver's steering with no need of switching strategies between the driver and the lane keeping control. A feedforward and a feedback controllers are designed by Ishida and Gayko (2004) to support the driver in order to reduce his/her workload without reducing the situation awareness and motivation of the driver. The lane keeping system proposed by Minoiu-Enache et al. (2009b) uses a switching strategy during diminished driving capability or driver inattentiveness to help the controller to fully replace the driver.

Such activation strategy seems to be the most adequate as according to ergonomic and psychology studies (Hoc et al., 2009) as the driver usually does not have time to think and plan in emergency situations. There is only time to react in order to re-establish a safe state, therefore sharing the control with the driver is not really an advantage and in these cases it is better that the controller takes completely the responsibility during the control duration. As a consequence, this paper addresses the problem of designing a steering controller that switches between the driver and the assistance system, based on the attentiveness of the driver and the risk of lane departure during lane keeping.

The controller synthesis proposed in Minoiu-Enache et al. (2009a) is able to compute by means of Bilinear Matrix Inequalities (BMI), a minimal ellipsoidal invariant set that ensures the stability of the closed loop system at its activation, even in the presence of road curvatures (considered as disturbance) and taking into account bounds in the input control. This paper enhances these results by using a dynamic state feedback controller, which ensures zero lateral offset in steady state, even in curved road section characterised by nonzero curvature. Simulations results of the dynamic state feedback have been presented by the authors in (Benine-Neto et al., 2010), whereas in this paper, the controller have been implemented in a prototype vehicle and results include practical experimentation on a test track. A second extension of the previous work consists in the improvement of the damping characteristics of the closed-loop response by additional constraints for pole clustering.

Section 2 presents the vehicle model used for the control synthesis, as well as a model for the disturbance, which is taken into account in the internal model design. In section 3 the control objectives and synthesis are presented. The activation strategy of the steering assistance system is also presented in this section. Experiments of the system on Carsim environment and on a test track are shown in section 4 confirming the performance of the controller and activation strategy as a lane keeping assistance. The practical experiments 
Model Reference Based Vehicle Lateral Control for Lane Departure Avoidance 5

involve sharper curves than those specified in the design phase of the controller while even more severe conditions such as the test standard ISO/DIS 3888 are evaluated in Carsim environment. These tests also allow the evaluation the controller performance in situations not taken into account in the design phase, such as lateral tyre force saturation. Section 5 concludes the work providing some perspectives for future work.

\section{Vehicle model}

According to Ackermann et al. (1995), a single track vehicle model is considered to capture the essential vehicle lateral dynamics. It is developed under the assumption that wheel sideslip angles remain small, therefore considering a linearised model of the lateral tyre forces. The proposed controller is intended to be used in situations of unintended lane departure, in which the lateral tyre forces are not saturated. Hence, the single track vehicle model is adequate for the control design phase.

The front and rear wheels are represented each by a single wheel located at the centre of the axle and only the planar motion of the vehicle is considered, as depicted in Figure 1. The involved model variables are the vehicle sideslip angle $\beta$ and the vehicle yaw rate $r$. The control input is the steering angle, denoted by $\delta_{f}$.

$$
\left[\begin{array}{c}
\dot{\beta} \\
\dot{r}
\end{array}\right]=\left[\begin{array}{ll}
a_{11} & a_{12} \\
a_{21} & a_{22}
\end{array}\right]\left[\begin{array}{l}
\beta \\
r
\end{array}\right]+\left[\begin{array}{l}
b_{11} \\
b_{21}
\end{array}\right] \delta_{f},
$$

with:

$$
\begin{array}{lll}
a_{11}=-\frac{2\left(c_{f}+c_{r}\right)}{m v}, & a_{12}=-1-\frac{2\left(c_{f} l_{f}-c_{r} l_{r}\right)}{m v^{2}}, & b_{11}=\frac{2 c_{f}}{m v}, \\
a_{21}=-\frac{2\left(c_{f} l_{f}-c_{r} l_{r}\right)}{J}, & a_{22}=-\frac{2\left(c_{f} l_{f}^{2}+c_{r} l_{r}^{2}\right)}{J v}, & b_{21}=\frac{2 c_{f} l_{f}}{J} .
\end{array}
$$

The definition and the numerical values of the above parameters are given in Table 1.

Two more equations have to be included in the model for lane keeping objectives. The corresponding variables are: the relative yaw angle, denoted by $\psi_{L}$ which is the difference between vehicle heading angle $\psi$ and desired heading angle $\psi_{d}$, as shown in Figure 1; and the lateral offset $y_{L}$ at a look-ahead distance $l_{s}$. The equations describing the evolution of these variables are:

$$
\begin{aligned}
& \dot{\psi}_{L}=r-v \rho, \\
& \dot{y}_{L}=v \beta+l_{s} r+v \psi_{L},
\end{aligned}
$$

where $\rho$ is the road curvature, defined as $\rho=1 / R$, with $R$ the curvature radius. This exogenous input is considered to be bounded by a maximum value of road curvature, $|\rho| \leq \rho_{\max }$. A normalized variable $w$ that permits a parameterization of the road curvature $\rho$ can be defined as:

$$
w=\frac{\rho}{\rho_{\max }} .
$$


Considering equations (1) and (3) a linear model of the vehicle lateral motion can be written as:

$$
\left\{\begin{array}{l}
\dot{\bar{x}}=\bar{A} \bar{x}+\bar{B}_{u} u+\bar{B}_{w} w \\
\bar{y}=\bar{x}, \quad \bar{x} \in \mathbb{R}^{4}, u \in \mathbb{R}^{1}, w \in \mathbb{R}^{1},
\end{array}\right.
$$

where $\bar{x} \triangleq\left[\beta, r, \psi_{L}, y_{L}\right]^{T}$ is the state vector, $u$ is the control input corresponding to the steering angle $\delta_{f}$ and the matrices describing the linear system are:

$$
\bar{A}=\left[\begin{array}{cccc}
a_{11} & a_{12} & 0 & 0 \\
a_{21} & a_{22} & 0 & 0 \\
0 & 1 & 0 & 0 \\
v & l_{s} & v & 0
\end{array}\right], \quad \bar{B}_{u}=\left[\begin{array}{c}
b_{11} \\
b_{21} \\
0 \\
0
\end{array}\right], \quad \bar{B}_{w}=\left[\begin{array}{c}
0 \\
0 \\
-v \rho_{\max } \\
0
\end{array}\right] .
$$

One of the main limitations of the linear model (5) is that the road adherence is considered constant (implicitly in the cornering stiffness parameters $c_{f}$ and $c_{r}$ ). Despite of this shortcoming, this simplified model is adequate for the control synthesis, whereas the validation of the control strategy is carried out on a experimental vehicle CarSim model which includes non-linearities, as shown in section-4.

In order to design a controller that is able to avoid lane departure despite road curvature, it is required to consider the exogenous input within the vehicle model, building an internal model. Such control technique among with the control objective and synthesis are detailed in the following section.

\section{Control Strategy}

In this section, the design requirements of the controllers for the lane departure avoidance system are presented. The development of an internal model in order to incorporate the perturbation (road curvature, $\rho$ ) into the vehicle model is also discussed. This contribution enables the convergence of the lateral offset to zero in steady state. Minoiu-Enache et al. (2009a) proposed a synthesis of state feedback controller by solving an optimisation problem subjected to Lyapunov-based BMI constraints, which are used to guarantee invariant set properties. As an extension to this work, part of this section is dedicated to show enhancement to this controller synthesis by considering pole clustering constraints in order improve damping characteristic of the closed loop system.

\subsection{Control Objectives for Lane Departure Avoidance}

In order to design a lane departure avoidance system that performs satisfactorily even in curves, it is essential to take the road curvature into account in the control synthesis. The controller is intended to operate within the linear behaviour of the lateral tyre forces. The following requirements are imposed on the control synthesis:

- The controller must ensure asymptotic stability of the closed loop system.

- The vehicle state trajectories should be bounded in order to avoid vehicle instability and excursions out of the lane. 
Model Reference Based Vehicle Lateral Control for Lane Departure Avoidance 7

- In order to ensure satisfactory performance, the vehicle must be driven to the centre of the lane as fast as possible without detriment of the vehicle stability.

- The vehicle must present zero lateral offset in steady state conditions, even while negotiating curves.

- The control input must be bounded in order to avoid damage of the actuators.

Based on these requirements, the design of a state feedback controller for lane departure avoidance is shown in the subsequent part.

\subsection{Internal model}

According to Francis and Wonham (1976), an adequate strategy for the design of control laws, considering parameter uncertainties or perturbations, consists in integrating the perturbations in the controller by means of an internal model, in which the disturbances are represented as a family of known functions.

Road building standards define that clothoids are to be used to smoothly interconnect straight roads to constant curvature roads (Rajamani, 2006). Clothoids are based on Fresnel Integral with shape defined by a single parameter $c$. Considering $l$ the distance measured along the clothoid, the road curvature is defined by :

$$
\rho(l)=\frac{1}{c^{2}} l
$$

At constant speed, $l(t)=v t$, which implies that the road curvature increases linearly with respect to curviligne abscissa and thus to time:

$$
\rho(t)=\frac{v}{c^{2}} t
$$

Thus, the disturbances on the model used in the design of the lane departure avoidance system consist of constant values and ramps.

Noting where $\mathcal{L}$ is the Laplace transform operator, the transfer function $\mathcal{L}\left\{y_{L}\right\} / \mathcal{L}\{\rho\}$ of closed loop system formed by (5) and state feedback controller of the form $u=\bar{K} \bar{x}$ is given by :

$$
\frac{\mathcal{L}\left\{y_{L}\right\}}{\mathcal{L}\{\rho\}}=\frac{\left(s-z_{1}\right)\left(s-z_{2}\right)}{\left(s-p_{1}\right)\left(s-p_{2}\right)\left(s-p_{3}\right)\left(s-p_{4}\right)}
$$

where the zeros $z_{i}$ and poles $p_{i}$ for $\{i=1,2,3,4\}$ depend on the vehicle parameters.

Such control action is not able to reject the disturbances due to the road curvature (such as constant values and ramps) and ensure a zero lateral offset in steady state. For that, the transfer function $\mathcal{L}\left\{y_{L}\right\} / \mathcal{L}\{\rho\}$ must present a double zero at the origin of the complex plane, which is obtained by a double integration of the lateral offset to the control input, i.e. $u=\bar{K} \bar{x}+k_{I 1} \int_{0}^{t} y_{L} d \tau+k_{I 2} \int_{0}^{t} \int_{0}^{\tau} y_{L} d \tau d \nu$.

As the control synthesis applied in this work (shown in details in section 3.3) is based on a state feedback controller, a state space representation of the internal model (dynamics of 
integrators) is more adequate. Thus the internal model consists of the states $\alpha=\left[\alpha_{0}, \alpha_{1}\right]^{T}$, which uses the lateral offset $y_{L}$ as input, as follows:

$$
\dot{\alpha}=\left[\begin{array}{ll}
0 & 1 \\
0 & 0
\end{array}\right] \alpha+\left[\begin{array}{c}
0 \\
y_{L}
\end{array}\right]
$$

These additional variables introduced by the internal model are included in the state vector of (5), which yields $x \triangleq\left[\beta, r, \psi_{L}, y_{L}, \alpha_{0}, \alpha_{1}\right]^{T}$, and the augmented system becomes,

$$
\left\{\begin{array}{l}
\dot{x}=A x+B_{u} u+B_{w} w \\
y=x,
\end{array} \quad x \in \mathbb{R}^{6}, u \in \mathbb{R}^{1}, w \in \mathbb{R}^{1} .\right.
$$

Accordingly the system matrices become:

$$
A=\left[\begin{array}{cccccc}
a_{11} & a_{12} & 0 & 0 & 0 & 0 \\
a_{21} & a_{22} & 0 & 0 & 0 & 0 \\
0 & 1 & 0 & 0 & 0 & 0 \\
v & l_{s} & v & 0 & 0 & 0 \\
0 & 0 & 0 & 0 & 0 & 1 \\
0 & 0 & 0 & 1 & 0 & 0
\end{array}\right], \quad B_{u}=\left[\begin{array}{c}
b_{11} \\
b_{21} \\
0 \\
0 \\
0 \\
0
\end{array}\right], \quad B_{w}=\left[\begin{array}{c}
0 \\
0 \\
-v \rho_{\max } \\
0 \\
0 \\
0
\end{array}\right] .
$$

Applying in system (10) a state feedback of the form $u=K x$, with $K=$ $\left[k_{1}, k_{2}, k_{3}, k_{4}, k_{5}, k_{6}\right]$, the closed loop system becomes:

$$
\dot{x}=\left(A+B_{u} K\right) x+B_{w} w .
$$

and its equilibrium point is:

$$
x_{e q}=-w \rho_{\max }\left[\begin{array}{c}
\frac{\left(b_{1} a_{22}-a_{12} b_{2}\right)}{\left(-b_{2} a_{11}+b_{1} a_{21}\right)} v \\
-v \\
\frac{\left(b_{1} l_{s} a_{21}-b_{1} a_{22} v-b_{2} a_{11} l_{s}+b_{2} a_{12} v\right)}{-b_{2} a_{11}+b_{1} a_{21}} \\
0 \\
x_{e q 5} \\
0
\end{array}\right]
$$

in which

$$
\begin{aligned}
x_{e q 5}= & -\left(v b_{21} k_{3} a_{12}-b_{21} k_{3} l_{s} a_{11}+v a_{11} b_{21} k_{2}-v b_{21} k_{1} a_{12}-v b_{11} k_{3} a_{22}+b_{11} k_{3} l_{s} a_{21}\right. \\
& \left.+v b_{11} k_{1} a_{22}-v a_{21} a_{12}+v a_{11} a_{22}-v a_{21} b_{11} k_{2}\right) /\left(k_{5} v\left(-b_{21} a_{11}+b_{11} a_{21}\right)\right) v
\end{aligned}
$$

From (12) it can be observed that in steady-state the yaw rate is equal to $v \rho$ and the lateral offset is equal to zero. Therefore, by choosing adequately the state feedback gains, it is possible to stabilise (11) and steer the vehicle to a zero lateral offset condition even in the presence of disturbances. Thus, the control strategy using the internal model fulfils the control objective of converging to the centre of the lane while negotiating curves.

The subsequent part presents the synthesis of the dynamical state feedback gain in order to ensure that the other control objectives are achieved. 
Model Reference Based Vehicle Lateral Control for Lane Departure Avoidance 9

\subsection{Controller synthesis}

Since it is intended to apply a control law that enables the vehicle to perform curves, $\rho \neq 0$, the equilibrium point (12) is no longer fixed at the origin (as in the case of straight lines). Therefore, to make use of the Lyapunov theory of stability, it is necessary to ensure that the state trajectories converge to an invariant set containing all the equilibrium points.

As presented by Minoiu-Enache et al. (2009a), it is possible, by means of BMI optimisation procedure, to find simultaneously a state feedback gain and a quadratic Lyapunov function, which guarantee the invariant set properties even in the presence of disturbances.

\subsubsection{BMI contraints for Lyapunov invariant set}

An ellipsoidal invariant set of the form:

$$
\varepsilon(P) \triangleq\left\{x \in \mathbb{R}^{n}: x^{T} P x \leq 1\right\} \text {, with } P=P^{T} \text { and } P \succ 0,
$$

with $n=6$ for model (10), can be obtained from a quadratic Lyapunov function:

$$
V(x)=x^{T} P x, \text { with } P \succ 0 \text { and } \dot{V}(x)<0 .
$$

The invariant set must contain all trajectories starting from a subset which represents the states at the activation of the assistance system. This subset of initial conditions is a polytope $L\left(T^{N}\right)$ defined as:

$$
x \in L\left(T^{N}\right) \triangleq\left\{x \in \mathbb{R}^{6}:\left|T^{N} x\right| \leq 1\right\},
$$

where $T^{N} \in \mathbb{R}^{6 x 6}$ is a diagonal matrix with the following elements:

$$
T^{N} \triangleq \operatorname{diag}\left[\left(\beta^{N}\right)^{-1},\left(r^{N}\right)^{-1},\left(\psi_{L}^{N}\right)^{-1},\left(y_{L}^{N}\right)^{-1},\left(\alpha_{0}^{N}\right)^{-1},\left(\alpha_{1}^{N}\right)^{-1}\right]
$$

where the values $\beta^{N}$ and $r^{N}$ can be set as the equilibrium point of (11) for $\rho=\rho_{\max }$ and the remaining parameters are chosen based on safety conditions such as maximum vehicle positioning on the road.

Minimising the ellipsoid that contains the polytope (15) at the same time as satisfying the conditions $\dot{V}<0, V(x) \geq 1, w^{T} w \leq 1$ can be expressed in terms of a bilinear matrix inequality optimisation problem, by using the S-procedure (Boyd et al., 1994) as follows:

Minimise:

$$
\operatorname{tr}(Q), \operatorname{det}(Q) \text { or } \lambda_{\max }(Q)
$$

Subjected to:

$$
\begin{gathered}
\eta \succ 0, \\
Q \succ 0, \\
\left(\begin{array}{rr}
Q A^{T}+Y^{T} B_{u}^{T}+A Q+B_{u} Y+\eta Q & B_{w} \\
B_{w}^{T} & -\eta
\end{array}\right) \preceq 0, \\
\left(\begin{array}{cc}
1 & q_{i}^{T} \\
q_{i} & Q
\end{array}\right) \succeq 0, \quad i=1, \ldots, g / 2,
\end{gathered}
$$


where $\eta$ is a real constant, $Q=P^{-1}, Y=K P^{-1}$, and $q_{i}$ represents each of the $g=64$ vertices of the polytope (15).

The ellipsoidal invariant set obtained form (17), delimits the bounds of the state trajectories despite the disturbance satisfying the control strategy.

Another control objective requires bounds on the control input, which can be achieved by adding a constraint to the optimisation problem. This constraint is important not only to limit the control input with respect to the actuator physical limitations but also to keep the vehicle dynamics within the linear behaviour, avoiding excessive lateral accelerations and saturation of the lateral tire forces. The constraint can be expressed as:

$$
\left(\begin{array}{cc}
1 & \frac{1}{\delta_{f}^{\text {max }}} Y \\
\frac{1}{\delta_{f}^{\text {max }}} Y^{T} & Q
\end{array}\right) \succeq 0,
$$

where $\delta_{f}^{\max }$ is the maximum steering input used in the control design phase.

Whereas the contribution of the additional dynamics from the internal model improve the steady state performance of the lane keeping system, as shown in section 3.2 , the transient performance can also be enhanced by including a constraint for pole clustering, as an extension of the control synthesis proposed by Minoiu-Enache et al. (2009a).

\subsubsection{Linear matrix inequality constraint for pole clustering}

In order to enhance the damping characteristic of the closed loop response, constraints can be included to specify regions where the poles can be located. A constraint for pole clustering defining a conic sector of angle $\theta$ centred at the origin Chiali and Gahinet (1996), as shown in Figure 2, can be described as:

$$
\left(\begin{array}{ll}
\sin \theta\left[\begin{array}{l}
A Q+Q A^{T} \\
+B_{w} Y+Y^{T} B_{w}^{T}
\end{array}\right] & \cos \theta\left[\begin{array}{l}
A Q-Q A^{T} \\
+B_{w} Y-Y^{T} B_{w}^{T}
\end{array}\right] \\
\cos \theta\left[\begin{array}{l}
-A Q+Q A^{T} \\
-B_{w} Y+Y^{T} B_{w}^{T}
\end{array}\right] & \sin \theta\left[\begin{array}{l}
A Q+Q A^{T} \\
+B_{w} Y+Y^{T} B_{w}^{T}
\end{array}\right]
\end{array}\right) \prec 0
$$

If the optimisation problem composed of (17), (18) and (19) is feasible, the resulting controller is able to reject the disturbances of road curvature and it ensures that all the state trajectories are contained in the invariant set $\varepsilon(P)$. Moreover, the pole clustering condition (19) ensures that all eigenvalues have negative real parts, therefore the linear system (11) is asymptotically stable even in the presence of disturbances. Thus, by taking this constraint into account, all requirements of the the controller, as listed in 3.1, are met.

\subsection{Steering Assistance Activation Law}

The human interactions play an important role in the driving assistance systems, therefore an adequate activation strategy is required. In order to avoid an intrusive assistance that may not be well accepted by drivers, it is important to consider the driver awareness, as well as the risk of lane departure or collision accidents.

The assessments of driver's awareness can be found for instance in the works of Tran and Trivedi (2010) and Trivedi and Cheng (2007), while McCall and Trivedi (2006) present 
Model Reference Based Vehicle Lateral Control for Lane Departure Avoidance 11

a survey of methods to estimate the risk of lane departure. Other sophisticated strategies can be used in the design of the driver assistance, but they are beyond the scope of this work, since it focuses the control synthesis and its performance.

Due to the simplicity of implementation, the strategy chosen for this work is similar to the one used in Minoiu-Enache et al. (2009b), which takes into account the driver's attentiveness as well as the risk of either lane departure during lane keeping manoeuvre.

The driver's attentiveness is estimated by measuring the driver's input torque on the steering wheel, denominated $\tau$. If $\tau<5 \mathrm{Nm}$ the driver is considered inattentive. The driver has priority and control of the vehicle whenever his awareness is recovered, which is corresponds to $\tau>2 \mathrm{Nm}$.

The risk of lane departure is estimated by the position of the front wheels with respect to a fixed strip of width $2 d$ in the centre of the lane.

The positions of the left (right) front wheels, $y_{l,(r)}$, can be described by the following:

$$
\begin{aligned}
& y_{l}=y_{L}+\left(l_{f}-l_{s}\right) \psi_{L}+\frac{a}{2}, \\
& y_{r}=y_{L}+\left(l_{f}-l_{s}\right) \psi_{L}-\frac{a}{2},
\end{aligned}
$$

where $a$ represents the vehicle width. Enforcing that the front wheels must remain inside the centred lane strip $\pm d$, yields:

$$
-\frac{2 d-a}{2} \leq y_{L}+\left(l_{f}-l_{s}\right) \psi_{L} \leq \frac{2 d-a}{2}
$$

This set, corresponding to the region between two parallel hyperplanes, can be written with respect to the state vector as:

$$
T \triangleq\left\{x \in R^{6}:|F x| \leq 1\right\}
$$

where $F=\left(0,0, \frac{2\left(l_{f}-l_{s}\right)}{2 d-a}, \frac{2}{2 d-a}, 0,0\right)$.

In order to ensure the invariant set property, the activation must take place inside the ellipsoid (13), therefore the risk of lane departure is considered when the vehicle leaves the set:

$$
G \triangleq\{\epsilon(P) \cap T\}
$$

The activation and deactivation of the assistance system follows:

- Activate if $(\tau<5 N m) \&(|F x| \geq 1) \&(x \in \epsilon(P))$

- Deactivate if $(\tau \geq 2 \mathrm{Nm})$,

where \& is the Boolean operation AND.

\subsection{Control Law Computation}

The software PENBMI was used to solve the BMI problem (17), (18) and (19). The maximum road curvature was considered $\rho_{\max }=0.005 \mathrm{~m}^{-1}$. The polytopic region $T^{N}$ was defined with the following values:

$$
T^{N}=[0.013,0.174,0.017,0.2,0.005,0.005] .
$$


The bound for control input was defined as $\left|\delta_{f}^{\max }\right|=5^{\circ}$ and the angle for pole clustering was chosen $\theta=30^{\circ}$. The computed gain from the optimisation problem (17) is ensured to stabilise asymptotically the system for bounded disturbances $|\rho| \leq \rho^{\max }$, since constraint (19) is satisfied and consequently all real parts of the eigenvalues of (11) are negative. For $v=15 \mathrm{~m} / \mathrm{s}$ the computed eigenvalues are:

$$
\lambda=\left[\begin{array}{c}
-6.7218+1.3347 i \\
-6.7218-1.3347 i \\
-2.1680 \\
-1.5181 \\
-0.4520 \\
-0.2470
\end{array}\right],
$$

and the corresponding gain is given by:

$$
K=[-0.1813,-0.0955,-0.9418,-0.0781,-0.0045,-0.0341]
$$

The implementation and performance analyses of the obtained control law in Carsim environment and in a prototype vehicle are discussed in the sequel.

\section{Results}

In order to verify the performance of the obtained state feedback gain (26), simulations have been carried out in CarSim environment taking into account a disturbance rejection situation. The implementation on a prototype vehicle and results obtained on the test track are discussed in section 4.2. The controller is also tested in an obstacle avoidance situation as shown in section 4.3 .

\subsection{Simulation Results on a CarSim Vehicle}

CarSim vehicle model MacAdam (1981) uses detailed nonlinear tire models according to combined slip theory and takes into account the major kinematics and compliance effects of the suspensions (nonlinear spring models) and steering systems which were neglected at the control design stage. The standard CarSim F-Class vehicle has a nonlinear second order speed depending rack and pinion ratio steering system; a realistic actuator with a bandwidth of $10 \mathrm{~Hz}$ is considered for the active steering.

In order to verify the control objective of zero steady state error while negotiating curves, the first simulation consists of a vehicle driving at $22 \mathrm{~m} / \mathrm{s}$ on a road with the geometrical trajectory as show in the first plot of Figure 3. The driver is considered to be inattentive throughout the simulation.

The other two plots of Figure 3 depict respectively the vehicle sideslip angle and yaw rate during the lane keeping manoeuvre.

The top plot of Figure 4 shows the lateral offset which clearly converges to zero despite of the increasingly road curvature, whereas the limited control input can be seen in the bottom plot.

Since the simulations results satisfactorily confirm the achievement of the control objectives, the same controller has been implemented in a prototype vehicle and the performance of the lane departure avoidance system has been evaluated in a test track as shown in the sequel. 
Model Reference Based Vehicle Lateral Control for Lane Departure Avoidance 13

\subsection{Practical Implementation}

The experimental vehicle used in the practical implementation (Figure 5) is equipped with a CORREVIT sensor to measure the vehicle sideslip angle $\beta$; an Inertial Navigation System to measure the vehicle yaw rate $r$ and an odometer used to compute the vehicle longitudinal speed. A DC-motor mounted on the steering column provides the assistance torque through a PID controller which is used to track the control input in terms of steering angle $\delta_{f}$. An optical encoder is used to measure the steering angle, and load cell sensors integrated on the steering wheel are used to measure the driver torque.

A video camera is used to detect the lane markers by the vision algorithms of Labayrade et al. (2006) permitting the measurements of lateral offset at look-ahead distance $y_{L}$ and relative yaw angle $\psi_{L}$. The whole control algorithm, including the image capturing and processing, runs with a period of $0.04 s$.

The tests took place on a test track located in Satory-Versailles, $20 \mathrm{~km}$ west of Paris, France. The track is $3.5 \mathrm{~km}$ long consisting of typical road profiles as straight lines and bends of various radii. Figure 5 depicts an aerial view of the test track.

Two manoeuvres are presented, in both of them the vehicle longitudinal speed is $15 \pm$ $2 \mathrm{~m} / \mathrm{s}$ and the driver is considered inattentive in the beginning of the manoeuvre, but retakes control in the end.

The first manoeuvre consists of on an S-shaped turn, with first turn to the left, as it can be noticed with the bottom subplot of Figure 8 . The positioning of the vehicle on the lane is shown on Figure 6. The first subplot shows the relative yaw angle while in the second it is shown the position of the front wheels with respect to the lane, which is shown by the dashed-dot line. The activation occurs at $51 s$ approximately when the right wheel crosses the fixed centred strip of $\pm d$, depicted by the dashed line. The front wheels remain in the lane during the whole control action. The driver recovers attention at $63 \mathrm{~s}$, and the controller is deactivated, since he/she apply a steering torque greater then $2 \mathrm{Nm}$.

The dynamics of vehicle during the intervention of the lane keeping system can be seen in Figure 7. The vehicle sideslip angle, yaw rate and longitudinal speed are depicted. The required control input is shown in the top subplot of Figure 8. In the bottom subplot it can be seen the road curvature for the corresponding part of the track. Even though the values of the road curvature are larger than the bound chosen in the design phase $\left(\rho_{\max }=0.005 \mathrm{~m}^{-1}\right)$, the controller performs satisfactory keeping the vehicle within the lane limits.

Another manoeuvre is carried out in order to show the lane keeping controller performance. As it can be seen by the road curvature of the test track depicted in Figure 11, this scenario corresponds to an inattentive driver on a curve to the right side, which is also sharper than the considered bound $\rho_{\max }$ in the design stage.

The activation, shown in the bottom subplot of Figure 9, takes place due to the positioning of the right front wheel, which reaches the centred strip on the interior side of the curve. Even though the correction induces a longer excursion of the vehicle near the exterior side of the lane, the performance is satisfactory, as the front wheels do not exit the lane. The relative yaw angle is plotted on the top subplot of Figure 9.

The dynamics of vehicle during the control action are illustrated on Figure 10. The subplot shows the vehicle sideslip angle, yaw rate and longitudinal speed respectively. Finally the required control input is shown in the top subplot of Figure 11.

Due to the satisfactory performance of the lane keeping system, obstacle avoidance manoeuvres with the same controller are performed in the CarSim simulation environment 
on a vehicle model similar to the experimental vehicle. The results are shown in the next section.

\subsection{Obstacle avoidance manoeuvre}

As an attempt to test the controller in different emergency situations, simulations on Carsim environment are carried out considering a double lane change manoeuvre from ISO/DIS3888 standard. This test is well known for being severe, as the vehicle is submitted to lateral tyre forces which enter the non-linear behaviour (which has been neglected in the design phase). It is usually applied for the validation of advanced driver assistance systems, commercially known as ESC (electronic stability control), which may include active steering, independently wheel braking and active suspension.

The path considered in the test is shown in Figure 12. The test is defined by a predetermined placement of cones on the road and the manoeuvre is carried out on a dry surface. The vehicle longitudinal speed is $25 \mathrm{~m} / \mathrm{s}$.

The resulting vehicle sideslip angle and the yaw rate are depicted in Figure 12. The lateral offset $y_{l}$ and the corresponding control action are shown in Figure 13. The controller achieves the path following with a reduced path following error in the lateral direction $(0.4 \mathrm{~m}$ as can be observed in the first subplot of Figure 13.

\section{Conclusions}

This work has proposed a lane keeping assistance system which takes into account simultaneously the attentiveness of the driver and the risk either of unintended lane departure. Moreover, it was shown that it is possible to reject the disturbances, steering the vehicle to zero lateral offset, by modelling the exogenous input (road curvature) into an internal model with two integration of the lateral offset signal. The compensation of the disturbances is guaranteed by the dynamic state feedback controller. The design of the controller also takes into account limitation in the control input.

The problem of finding a feedback gain that stabilises the system with bounded control input, can be casted as an BMI optimisation problem. It has been shown that pole-clustering constraint can been added to the BMI optimisation problem in order to improve the damping characteristic of the closed-loop response.

Simulations on CarSim environment showed that the proposed controller is able to ensure zero lateral offset in steady-state and satisfactorily transient response while rejecting a ramp disturbance corresponding to an increasingly road curvature.

The proposed control law has been implemented in a Peugeot 307 prototype vehicle and tested on the $3.5 \mathrm{Km}$ long test track located in Satory, $20 \mathrm{Km}$ west of Paris. The satisfactory performance of the practical tests confirm the use of the assistance as a lane departure avoidance system.

Moreover, simulations of a double lane-change manoeuvre have been performed with the CARSIM environment, showing satisfactorily performance of the controller when lateral tyre forces are beyond the linear behaviour in addition to its potential as a controller for obstacle avoidance. Such use is still to be evaluated on the test track, as well as testing the lane departure avoidance system on degraded road adherence.

Also as a perspective from this work, efforts should be concentrated in designing an output feedback controller in order to use only on-board vehicle sensors rendering the controller financially accessible for car manufactures. 
Model Reference Based Vehicle Lateral Control for Lane Departure Avoidance 15

\section{References}

Ackermann, J., Guldner, J., Sienel, W., Steinhauser, R., and Utkin, V. (1995). Linear and nonlinear controller design for robust automatic steering. Control Systems Technology, IEEE Transactions on, 3(1):132-143.

Benine-Neto, A., Mammar, S., Lusetti, B., and Scalzi, S. (2013). Piecewise affine control for lane departure avoidance. Vehicle System Dynamics, 51(8):1121-1150.

Benine-Neto, A., Scalzi, S., Mammar, S., and Netto, M. (2010). Dynamic controller for lane keeping and obstacle avoidance assistance system. In Intelligent Transportation Systems (ITSC), 2010 13th International IEEE Conference on, pages 1363-1368.

Boyd, S., Ghaoui, L. E., Feron, E., and Balakrishnan, V. (1994). Linear Matrix Inequalties in System and Control Theory, chapter 7. SIAM.

Broggi, A., Bertozzi, M., Fascioli, A., Bianco, C., and Piazzi, A. (1999). The argo autonomous vehicle's vision and control systems. International Journal of Intelligent Control and Systems, 3(4):409-441.

Cerone, V., Chinu, A., and Regruto, D. (2002). Experimental results in vision-based lane keeping for highway vehicles. In Proceedings of the IEEE American Control Conference. Anchorage, AK, USA, pages 869-874.

Cerone, V., Milanese, M., and Regruto, D. (2009). Combined automatic lane-keeping and driver's steering through a 2 dof control strategy. IEEE Transactions on Control Systems Technology, 17(1):135-142.

Chaib, S., S. Netto, M., and Mammar, S. (2004). H-infinity, adaptive, pid and fuzzy control: a comparison of controllers for vehicle lane keeping. In Proceedings of the IEEE Intelligent Vehicles Symposium, Parma, Italy, pages 139-144.

Chiali, M. and Gahinet, P. (1996). Hinf design with pole placement constraints: An Imi approach. IEEE Transactions on Automatic Control, 41(3):358-367.

Cremean, L., Foote, T., Gillula, J., Hines, G., Kogan, D., Kriechbaum, K., Lamb, J., Leibs, J., Lindzey, L., Rasmussen, C., et al. (2006). Alice: An information-rich autonomous vehicle for high-speed desert navigation. Journal of Field Robotics, 23(9):777-810.

Eidehall, A., Pohl, J., and Gustafsson, F. (2005). A new approach to lane guidance systems. In Intelligent Transportation Systems, 2005. Proceedings. 2005 IEEE, pages 108-112. IEEE.

Falcone, P., Borrelli, F., Asgari, J., Tseng, H., and Hrovat, D. (2007). Predictive active steering control for autonomous vehicle systems. Control Systems Technology, IEEE Transactions on, 15(3):566-580.

Francis, B. and Wonham, W. (1976). The internal model principle of control theory. Automatica, 12(5):457-465.

Fujiwara, Y. and Adachi, S. (2003). Steering assistance system for driver characteristics using gain scheduling control. In European Control conference (ECC), cambrigde, UK. 
Hessburg, T. and Tomizuka, M. (1991). A fuzzy rule-based controller for automotive vehicle guidance. Technical report, California Partners for Advanced Transit and Highways, PATH research report UCB-ITS-PRR-91-18.

Hoc, J., Young, M., and Blosseville, J. (2009). Cooperation between drivers and automation: implications for safety. Theoretical Issues in Ergonomics Science, 10(2):135-160.

Ishida, S. and Gayko, J. E. (2004). Development evaluation and introduction of a lane keeping assistance system. In Proceedings of the IEEE Intelligent Vehicles Symposium, Parma, Italy, pages 139-144.

Kang, J., Hindiyeh, R., Moon, S., Gerdes, J., and Yi, K. (2008). Design and testing of a controller for autonomous vehicle path tracking using gps/ins sensors. In Proceedings of the 17th IFAC World Congress, Seoul, Korea.

Kritayakirana, K. and Gerdes, J. (2012). Autonomous vehicle control at the limits of handling. Int. J. Vehicle Autonomous Systems, 10(4):271?296.

Kullack, A., Ehrenpfordt, I., Lemmer, K., and Eggert, F. (2008). Reflektas: lane departure prevention system based on behavioural control. IET Intelligent Transport System, 2(4):285-293.

Labayrade, R., Douret, J., Laneurit, J., and Chapuis, R. (2006). A reliable and robust lane detection system based on the parallel use of three algorithms for driving safety assistance. IEICE Transactions on Information and Systems, E89-D(7):2092-2100.

Leelavansuk, P., Shitamitsu, K., Mouri, H., and Nagai, M. (2002). Study on cooperative control of driver and lane-keeping assistance system. In Proceedings of Symposium on Advanced Vehicle Control (AVEC), Hiroshima, pages 219-224.

MacAdam, C. (1981). Application of an optimal preview control for simulation of closedloop automobile driving. IEEE Trans. on Systems, Man, and Cybernetics, 11:393-399.

Mammar, S., Minoiu-Enache, N., Glaser, S., Lusetti, B., and Benine-Neto, A. (2010). Lane keeping automation at tire saturation. In Proceedings of the IEEE American Control Conference, Baltimore, pages 6466-6471.

McCall, J. and Trivedi, M. M. (2006). Video-based lane estimation and tracking for driver assistance: Survey, system, and evaluation. IEEE Transactions on Intelligent Transportation System, 7(1):20-37.

Minoiu-Enache, N., Lusetti, B., Mammar, S., and Netto, M. (2009a). Assistance active de prévention des sorties de voie. prise en compte des virages. Journal Européen des Systèmes Automatisés, 43(6):615-646.

Minoiu-Enache, N., Netto, M., Mammar, S., and Lusetti, B. (2009b). Driver steering assistance for lane departure avoidance. Control Engineering Practice, 17(6):642 - 651.

Raharijaona, T., Duc, G., and Mammar, S. (2004). $h_{\infty}$ controller synthesis and analysis with application to lateral driving assistance. In Proceedings of IFAC Symposium on Advance in Automotive Control, Salerno, Italy.

Rajamani, R. (2006). Vehicle Dynamics and Control, chapter 2 - Lateral Vehicle Dynamics, pages $43-46$. Springer. 
Model Reference Based Vehicle Lateral Control for Lane Departure Avoidance 17

Rosseter, E. J. and Gerdes, J. C. (2006). Lyapunov based performance guarantees for potencial field lane keeping assistance system. Journal of Dynamic Systems, Measurement and Control - Transactions of the ASME, 128:510-522.

Shladover, S. E. (2007). Path at 20 - history and major milestones. IEEE Transactions on Intelligent Transportation Systems, 8(4):584-592.

Takahashi, A. and Asanuma, N. (2000). Introduction of honda asv-2 (advanced safety vehicle-phase 2). In Proceedings of the IEEE Intelligent Vehicles Symposium, Dearborn (MI), USA, pages 694-701.

Thrun, S., Montemerlo, M., Dahlkamp, H., Stavens, D., Aron, A., Diebel, J., Fong, P., Gale, J., Halpenny, M., Hoffmann, G., Lau, K., Oakley, C., Palatucci, M., Pratt, V., Stang, P., Strohband, S., Dupont, C., Jendrossek, L.-E., Koelen, C., Markey, C., Rummel, C., van Niekerk, J., Jensen, E., Alessandrini, P., Bradski, G., Davies, B., Ettinger, S., Kaehler, A., Nefian, A., and Mahoney, P. (2006). Stanley: The robot that won the darpa grand challenge. Journal of Field Robotics, 23(9):661-692.

Tran, C. and Trivedi, M. M. (2010). Towards a vision-based system exploring $3 \mathrm{~d}$ driver posture dynamics for driver assistance: Issues and possibilities. In Proceedings of the IEEE Intelligent Vehicles Symposium, San Diego, USA, pages 179-184.

Trivedi, M. M. and Cheng, S. Y. (2007). Holistic sensing and active displays for intelligent driver support systems. IEEE Computer Magazine, 40(5):60-68.

Urmson, C., Duggins, D., Jochem, T., Pomerleau, D., and Thorpe, C. (2008). From automated highways to urban challenges. In Proceedings of the 2008 IEEE International Conference on Vehicular Electronics and Safety, Columbus, OH, USA, pages 22-24.

Wu, S.-J., Chiang, H.-H., Perng, J.-W., Chen, C.-J., Wu, B.-F., and Lee, T.-T. (2008). The heterogeneous systems integration design and implementation for lane keeping on a vehicle. Intelligent Transportation Systems, IEEE Transactions on, 9(2):246-263. 


\section{List of Tables and Figures}

Table 1 Values of the vehicle parameters.

\begin{tabular}{ll}
\hline Parameter & Value \\
\hline$c_{f}$, front cornering stiffness & $40000 \mathrm{~N} / \mathrm{rad}$ \\
$c_{r}$, rear cornering stiffness & $35000 \mathrm{~N} / \mathrm{rad}$ \\
$l_{f}$, distance form CG to front axle & $1.22 \mathrm{~m}$ \\
$l_{r}$, distance form CG to rear axle & $1.44 \mathrm{~m}$ \\
$l_{s}$, look-ahead distance & $0.95 \mathrm{~m}$ \\
$a$, vehicle width & $1.5 \mathrm{~m}$ \\
$m$, total mass & $1600 \mathrm{~kg}$ \\
$J$, vehicle yaw moment of inertia & $2454 \mathrm{kgm}^{2}$ \\
$v$, longitudinal velocity & $15 \mathrm{~m} / \mathrm{s}$ \\
\hline
\end{tabular}

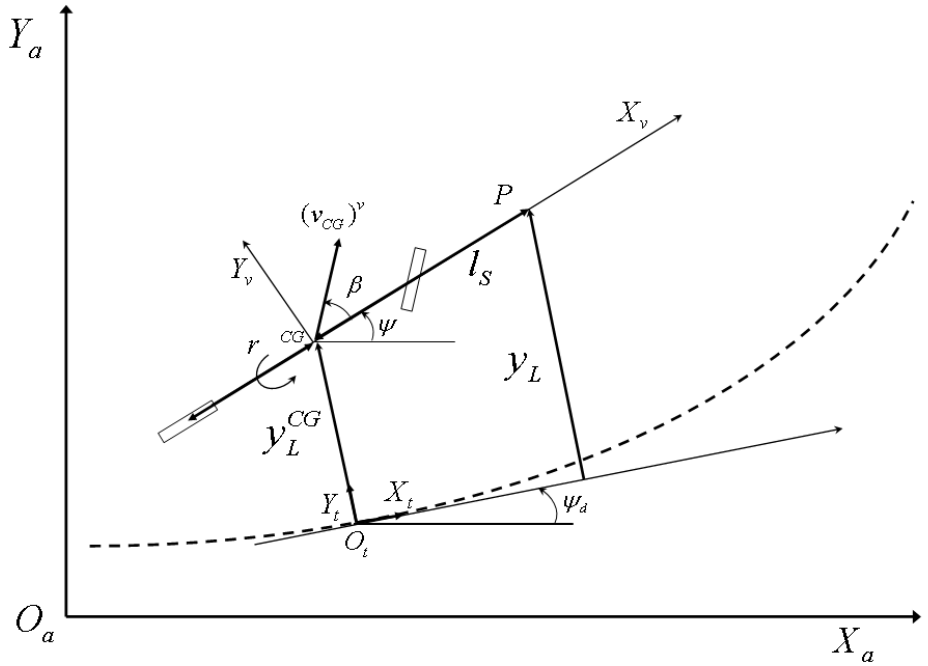

Figure 1 Dynamics and positioning variables of a single track vehicle model 
Model Reference Based Vehicle Lateral Control for Lane Departure Avoidance 19

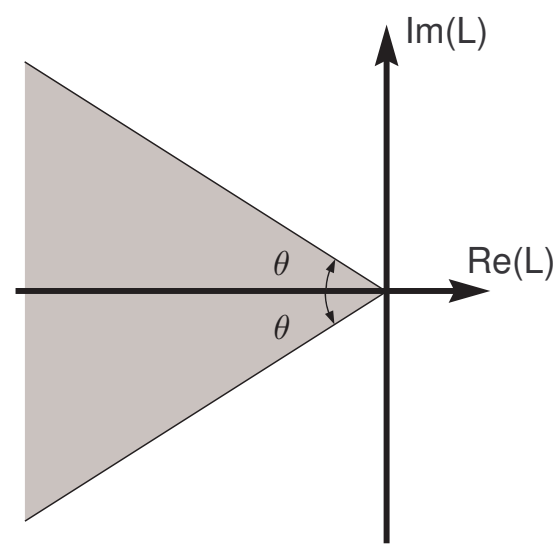

Figure 2 Conic region for pole clustering within angle $\theta$.
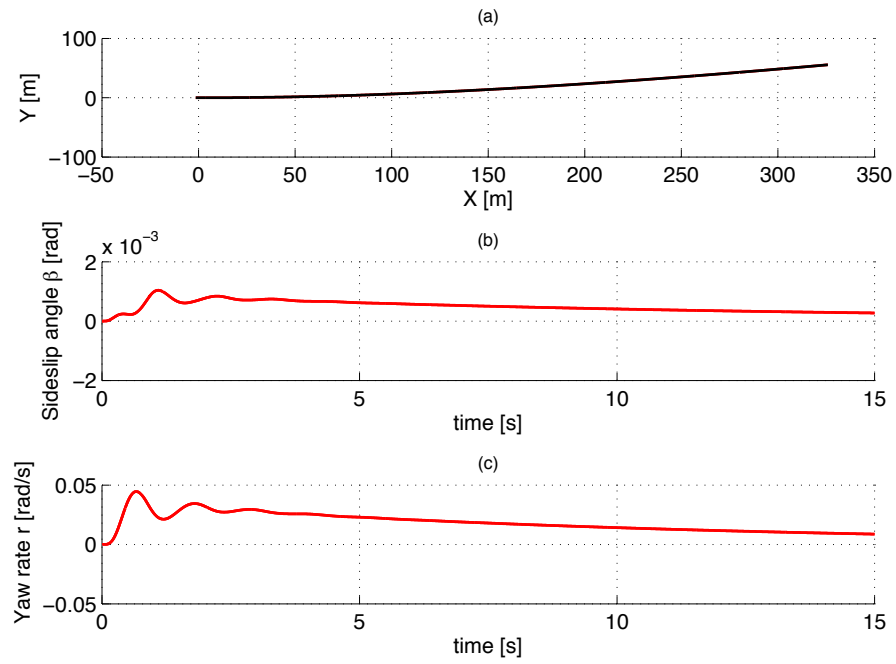

Figure 3 (a) Geometrical trajectory, (b) vehicle sideslip angle $\beta$ and (c) yaw rate $r$ in disturbance rejection manoeuvre at vehicle speed $v=22 \mathrm{~m} / \mathrm{s}$. 


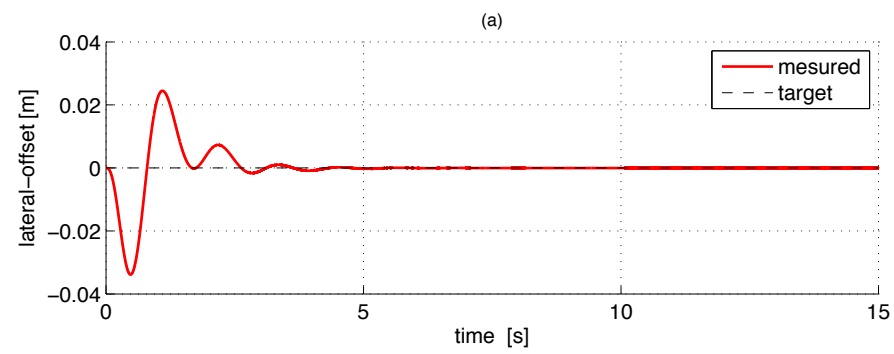

(b)

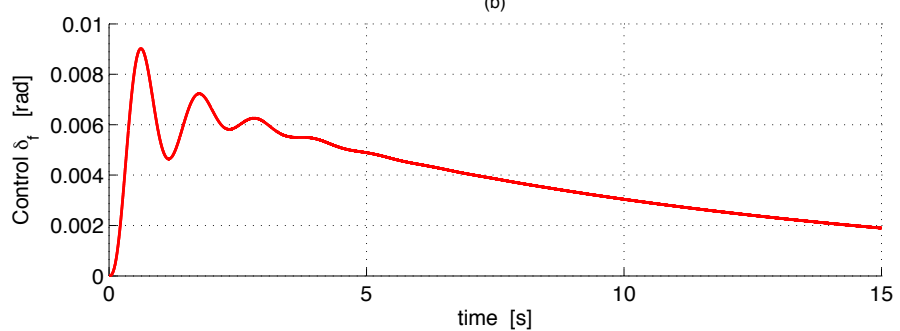

Figure 4 (a) Lateral offset $y_{L}$ and (b) control input $\delta_{f}$ of disturbance rejection manoeuvre at vehicle speed $v=22 \mathrm{~m} / \mathrm{s}$.
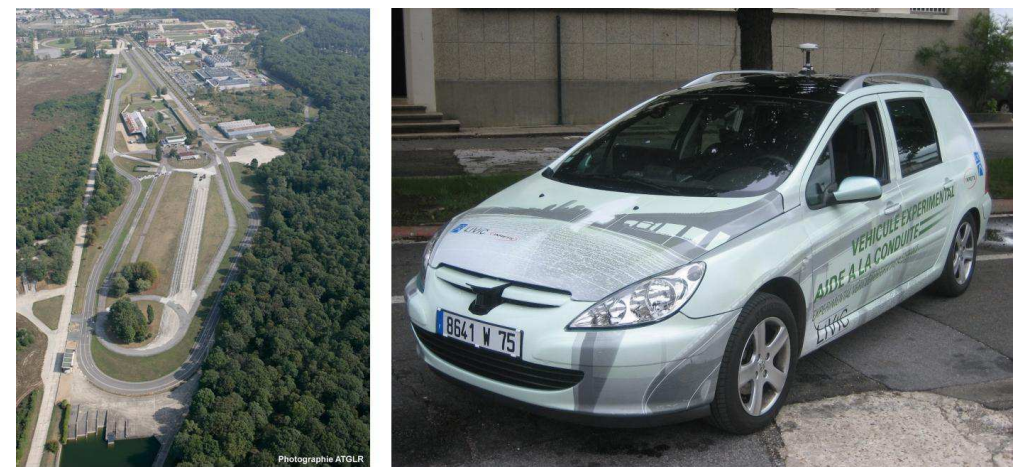

Figure 5 Aerial View from Satory-Versailles test track. Photo from: TGLR, Atelier Gérard Leroux, 13, rue Pierre Clavillier, 78800 Houilles, France and experimental vehicle. 
Model Reference Based Vehicle Lateral Control for Lane Departure Avoidance 21

(a)

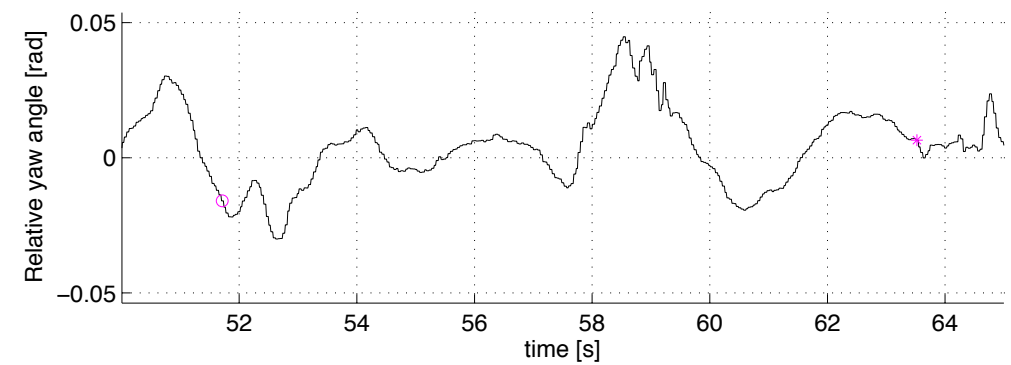

(b)

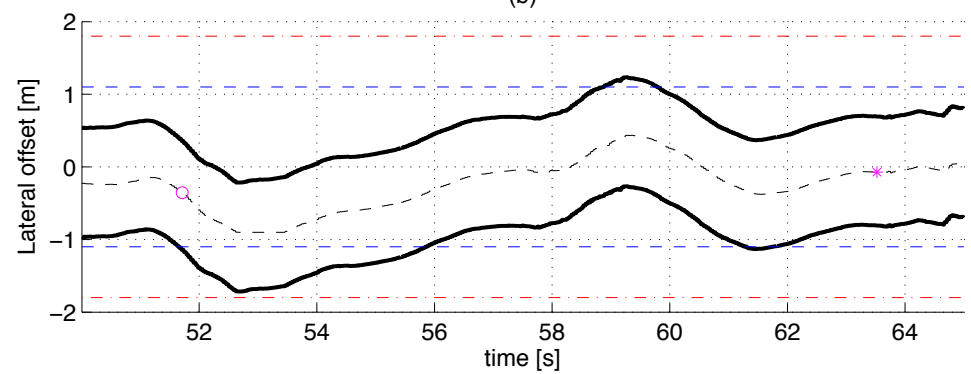

Figure 6 (a) Relative yaw angle, $\psi_{L}$ and (b) Lateral offset $y_{L}$ with estimated position of the front wheels with respect to lane.

(a)

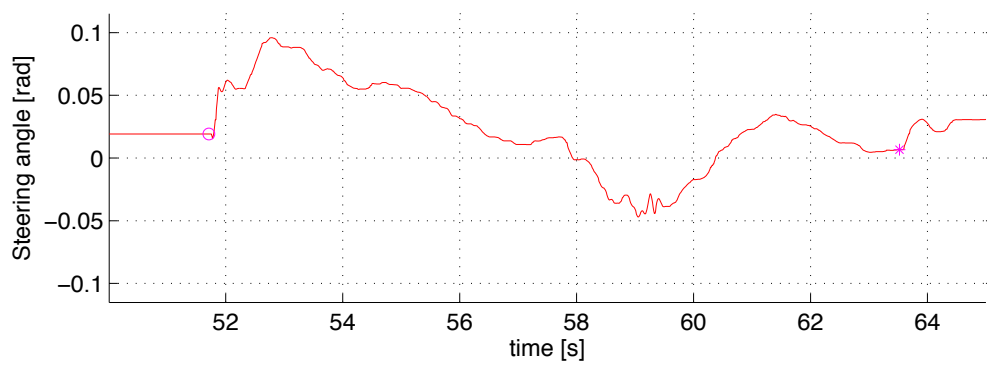

(b)

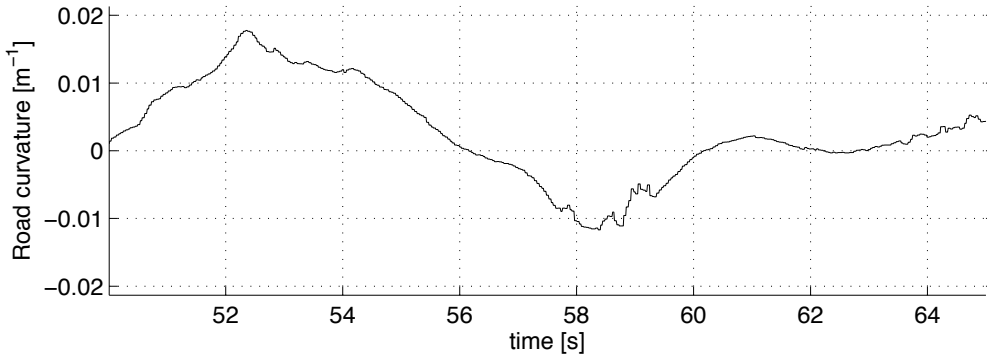

Figure 7 (a) Vehicle sidelip angle, (b) yaw rate and (c) lateral acceleration during control action to avoid lane departure. 


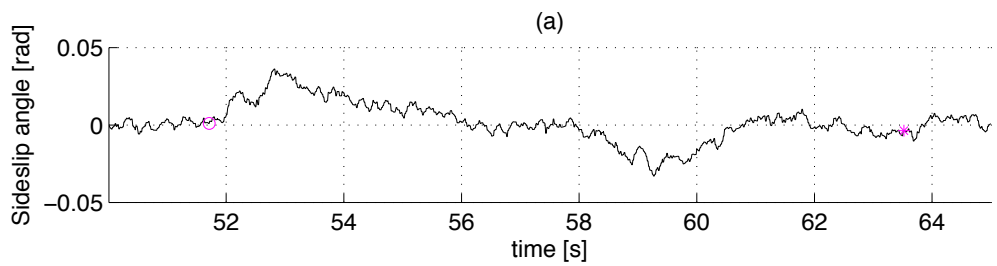

(b)
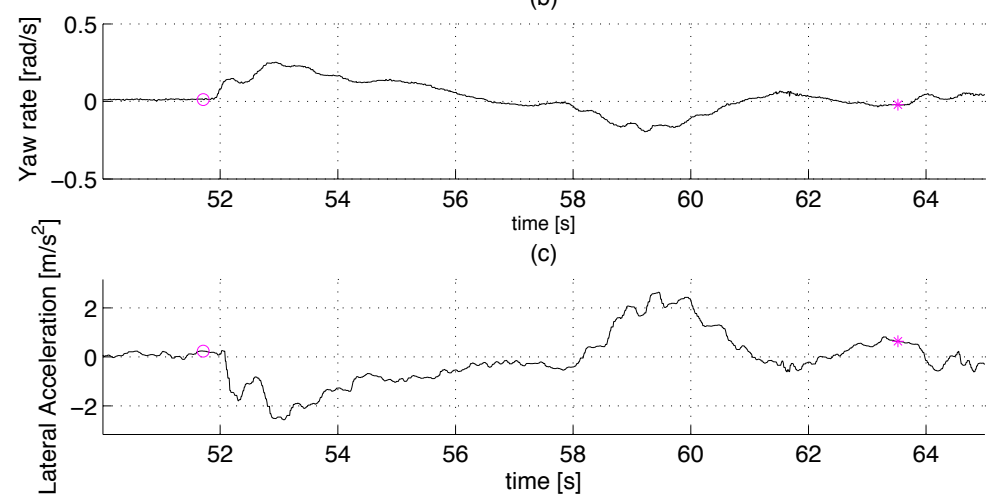

Figure 8 (a) Control input $\delta_{f}$ for lane departure avoidance manoeuvre and (b) road curvature $\rho$.

(a)

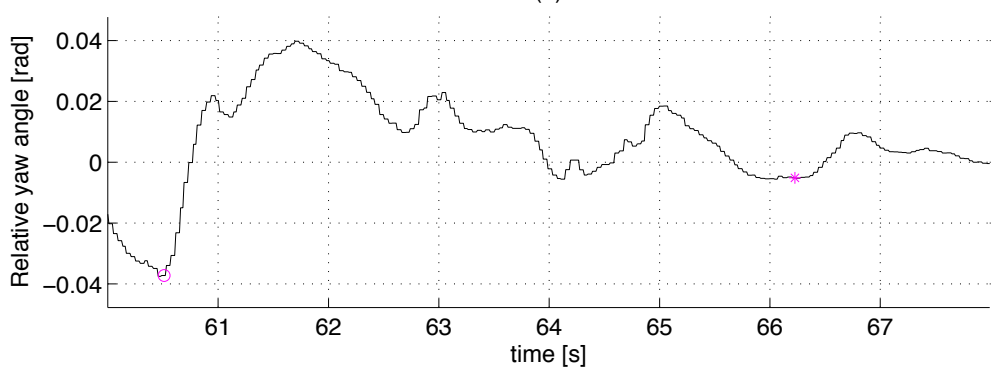

(b)

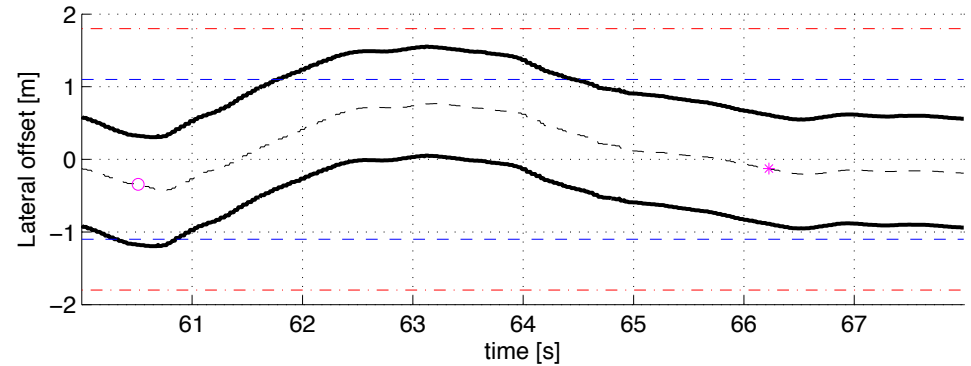

Figure 9 (a) Vehicle relative yaw angle $\psi_{L}$ and (b) lateral offset $y_{L}$ with estimated position of the front wheels with respect to lane during lane departure avoidance manoeuvre in curve. 
Model Reference Based Vehicle Lateral Control for Lane Departure Avoidance 23

(a)

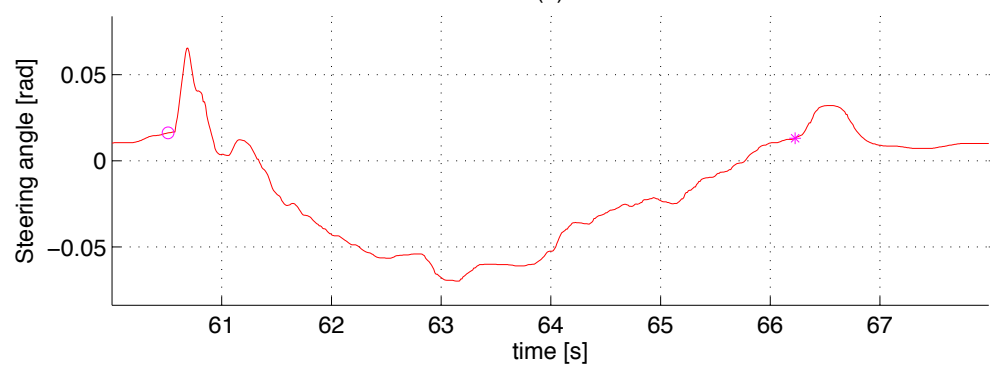

(b)

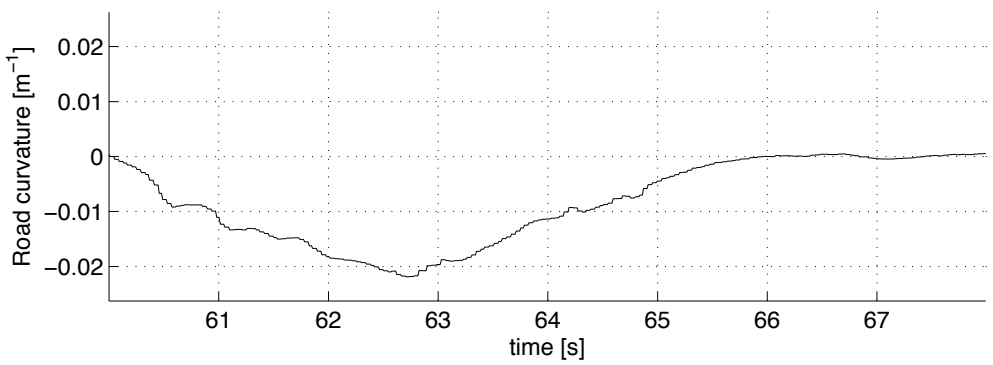

Figure 10 (a) Vehicle sideslip angle $\beta$, (b) yaw rate $r$ and (c) lateral acceleration during lane departure avoidance manoeuvre in curve.
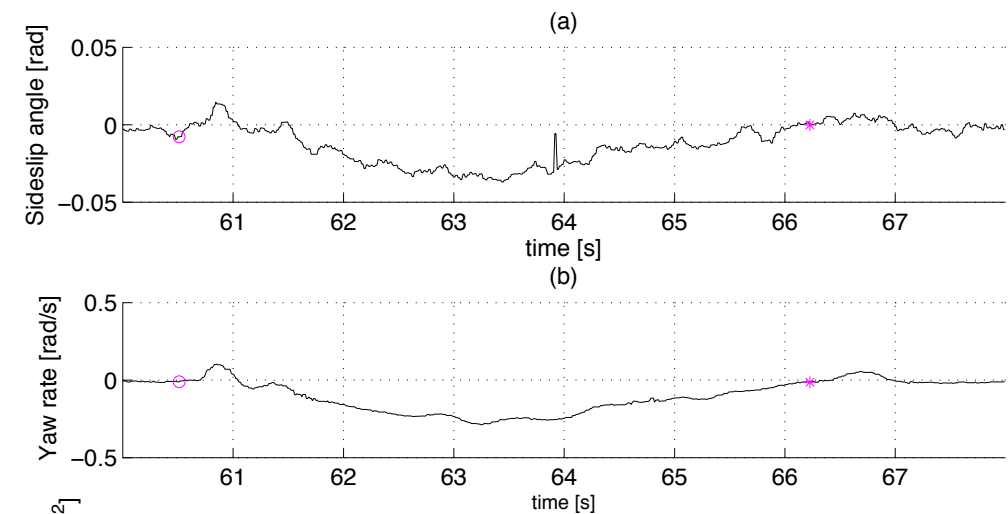

(c)

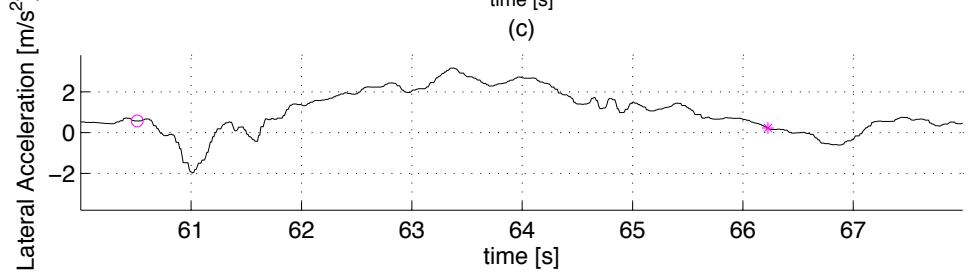

Figure 11 (a) Control input $\delta_{f}$ for lane departure avoidance manoeuvre and (b) road curvature $\rho$. 

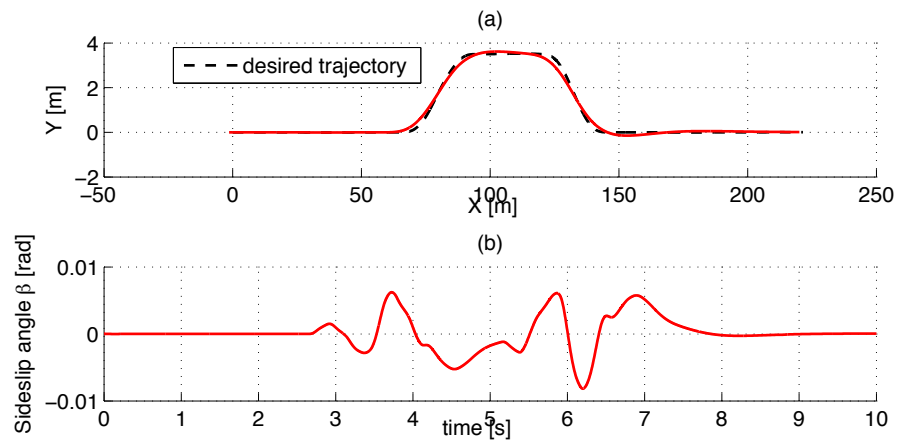

(c)

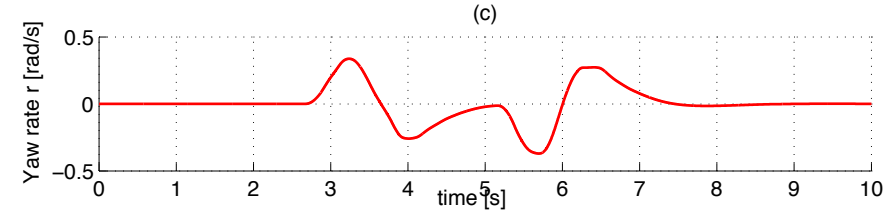

Figure 12 (a) Standard CarSim Moose test path, (b) vehicle sideslip angle $\beta$ and (c) yaw rate $r$ for manoeuvre performed at a longitudinal speed of $v=25 \mathrm{~m} / \mathrm{s}$.
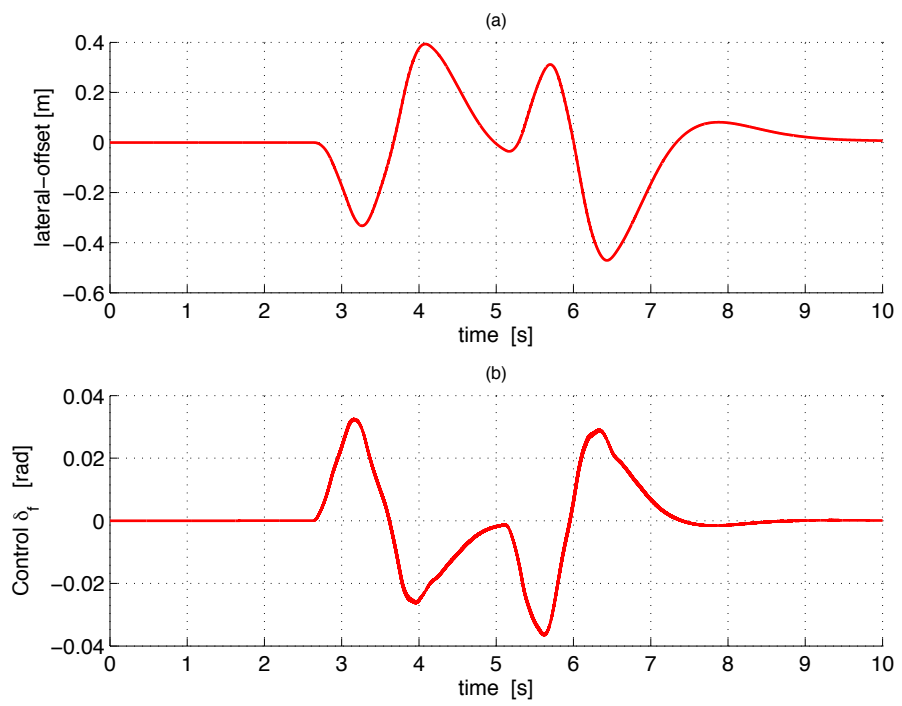

Figure 13 (a) Lateral offset $y_{L}$ and (b) control input $\delta_{f}$ for standard CarSim moose test manoeuvre performed at a longitudinal speed of $v=25 \mathrm{~m} / \mathrm{s}$. 